\title{
Nanopartikül Takviyeli Polimer Matrisli r-PET Geri Dönüşüm İpliklerinin Mikroyapı, Termal, Mekanik ve Antistatik Özelliklerinin İncelenmesi
}

\author{
Investigation of Microstructure, Thermal, Mechanical and Antistatic Properties of \\ Nanoparticle Reinforced Polymer Matrix r-PET Fiber Yarns
}

\author{
Kadir GÜNDOĞAN*1,a , Dilan KÖKSAL ÖZTÜRK ${ }^{2, b}$ \\ ${ }^{1}$ Uşak Üniversitesi, Mühendislik Fakültesi, Malzeme Bilimi ve Nanoteknoloji Mühendisliği Bölümü, 64200, Uşak \\ ${ }^{2}$ Uşak Üniversitesi, Mühendislik Fakültesi, Kimya Mühendisliği Bölümü, 64200, Uşak
}

\begin{abstract}
• Geliș tarihi / Received: 04.07.2019 • Düzeltilerek geliș tarihi / Received in revised form: 12.04.2020 • Kabul tarihi / Accepted: 15.04 .2020
\end{abstract}
\begin{abstract}
$\ddot{\mathbf{O} z}$
Son yıllarda nanoteknolojinin gelişmesiyle birlikte, polimer esaslı nanokompozitlerin üretimi ve kullanımı artmış, aynı zamanda bu kompozitlerin diğer alanlara uygulanabilirliği de önemli ölçüde gelişmiştir. Bu alanlardan biri de tekstildir. Tekstil uygulamalarında kullanılan polimer matrisli nanokompozitler sayesinde dayanımı daha yüksek, fonksiyonel, yüksek mukavemetli, antibakteriyel ve mekanik özellikleri iyileştirilmiş ürünler üretmek mümkün hale gelmiştir. Tekstilde kullanım amaçlı üretilen geri dönüşüm polimer matrisli nanokompozitler ise gün geçtikçe değerlenen diğer bir konudur. Günümüzde birçok firma atık PET polimerlerinden nanokompozitler üreterek çevreye katkıda bulunmaktadırlar. $\mathrm{Bu}$ çalışmada tekstilde kullanılan nanopartikül takviyeleriyle zenginleştirilmiş geri dönüşüm PET matrisli nanokompozitlerinin mekanik, mikroyapı, termal ve antistatik özellikleri incelenmiştir. Eriyikte birleştirme yöntemiyle üretilen $120 \mathrm{~nm}$ kalınlığındaki filamentlere takviye malzemesi olarak $\mathrm{ZnO}$, karbon nanotüp (CNT) ve $\mathrm{TiO}_{2}$ kullanılmıştır. Eklenen nanopartiküller ağırlıkça $\% 0.1, \% 0.3$ ve $\% 0.5$ oranındadır. Yapılan deneyler ve analizler sonucunda kompozitlere eklenen takviye malzemelerinin kompozitlerin mekanik, termal ve antistatik özelliklerini iyileştirdikleri görülmüştür. Kompozit malzemelere yapılan mukavemet testlerinde CNT takviyeli numunelerin sonuçlarıyla takviye verilmemiş PET polimerinin mukavemet değeri kıyaslandığında ortalama \%15 artış meydana geldiği görülmüş̧ür.
\end{abstract}

Anahtar kelimeler: Eriyikte Birleştirme, Geri Dönüştürülmüş PET, Karbon Nanotüp, Polimer Matrisli Nanokompozit, Titanyum Dioksit

\begin{abstract}
In recent years, polymer matrix nanocomposites production and usage ratio is increased and therwithal the applicability of these composites to other areas has also improved significantly. Textile industry is one of these areas. With the used of polymer matrix nanocomposites in textile applications, it become possible to produced improved products with high strength, functional, antibacterial and good mechanical properties. Textile recycling yarns get popular day by day. Lots of textile company producing recycled PET fiber yarns and this is contributed to the environment. In this study recycled PET polymer was used as a matrix and enriched nanoparticles to investigate mechanic, microstructure and thermal properties. Melting method was used for producing of nanocomposite multifilament yarns. Filament thickness was $120 \mathrm{~nm}$ and $\mathrm{TiO}_{2}, \mathrm{ZnO}$ and CNT was used as a reinforcement to ratio $\% 0.1, \% 0.3$, \%0.5 respectively. After analysis and experiments, it was seen clearly reinforcements was affected positively the mechnanical, microstructure and thermal properties of r-PET nanocomposites. According to the result of tensile strength tests, it was seen that CNT reinforcement increased tensile strength of r-PET polymer about \%15.
\end{abstract}

Keywords: Melt Mixing, Recycled PET, Carbon Nanotube, Polymer Matrix Nanocomposite, Titanium Dioxide

\footnotetext{
*a Kadir GÜNDOĞAN; kadir.gundogan@usak.edu.tr, Tel: (507) 777 18 79, orcid.org/0000-0001-6742-3110

${ }^{\mathrm{b}}$ orcid.org/0000-0002-6735-5506
} 


\section{Giriş}

Günümüzde değiş̧en çevre koşulları ve ekonomik zorluklar dünya genelinde atıkların geri kazanımı ile ilgili fikir arayışlarına neden olmuştur. Bunun yanı sıra atık geri kazanımı ile ilgili var olan teknolojilerde geliştirilmeye başlanmıştır. $\mathrm{Bu}$ atıklardan doğada en uzun süre bozulmadan kalanlarından biri polietilen terafatalat (PET) plastiğidir. Dünyada olduğu gibi ülkemizde de gömülerek yakılarak veya depolanarak bertaraf edilen PET atıkları doğada yüzyıllar boyu varlığını sürdürmektedir (Telli vd., 2012).

Polimerler yapıları itibariyle geri dönüşüme en elverişli malzemelerdir. $\mathrm{Bu}$ maddelerin çeşitli fiziksel ve kimyasal işlemlerden geçirilerek geri dönüşümlerinden elde edilen ikincil hammaddelerin birçok alanda kullanımı mümkündür. Ayrıca plastiklerin geri dönüşüm teknolojilerinde yaşanan gelişmeler de geri dönüşüm oranını arttırmakta ve bu da birçok endüstri için yeni hammadde kaynağının ortaya çıkmasını sağlamaktadır.

Dünya çapında yapılan araştırmalara göre PET plastiği geri dönüşüm için en uygun olan malzemelerden biridir (Awad ve Khalaf, 2016). PET polimerinin yaşamsal döngüsü incelendiğinde tüketimi en yüksek olan polimerlerin başında gelir. Bu polimer kolayca geri dönüştürülerek diğer polimerlere göre daha az özellik kaybıyla kendine daha fazla kullanım alanı bulan yeni bir hammadde olmaktadır.

PET polimerinin tekstil endüstrisinde kullanımı ise günümüzde giderek artmaktadır. Geri dönüşüm işleminden sonra eriyikten lif çekme yöntemiyle elde edilen r-PET liflerinin çevre dostu olması ve diğer liflere oranla üretiminde daha az maliyet getirmesi tekstil alanına katk1 sağlayacak uygulamalarda kullanılmasına zemin hazırlamaktadır. İşleme alınan PET plastiğinden elde edilen liflerin kalitesi geçtiği kimyasal temizlemeden sonra önemli ölçüde artar. Aynı zamanda r-PET daha az oluşum enerjisi gerektirmesi ve az miktarda karbon salınımıyla diğer lifler arasında öne çıkmaktadır. Bütün bu özellikler bir araya geldiğinde r-PET polimeri tektsil endüstrisi için tercih edilebilir bir hammadde haline gelebilir. Bu çalışmada üstün özelliklerinden ve çevre dostu olmasından dolayı r-PET polimeri tercih edilmiştir. Geridönüşüm yoluyla elde edilen r-PET ve diğer kullanıma uygun polimerlerden ikincil hammadde elde edilmesi; hem endüstrinin hammadde ihtiyacını azaltmakta, hem doğal kaynakların tükenmesi azalmakta hem de ekonomiye katkı sağlamaktadır.

Tekstil ve diğer endüstrilerde kullanılan polimer matrisli kompozitlerin üretim prosesleriyle nanoteknoloji ilgilenir. Nanoteknoloji nanoboyuta sahip yapilarla ve bu yapilara uygulanan proseslerle ilgilenen disiplinlerarası bir teknolojidir (Harry vd., 1996). Bu çalışmada rPET polimeri matris malzemesi olarak kullanılmış, üretilen kompozite mekanik ve antistatik özellikler kazandırılmak için takviye malzemeleri eklenmiş̧ir. Nano boyutta eklenen bu malzemeler sayesinde kompozit malzemelerin toplam yüzey alanları genişlemiş, böylece eklenen nano partiküllerin etkisi ile konvansiyonel malzemelere kıyasla çok daha başarılı olmuştur. Genellikle polimer maddelerin belirli özellikleri ile liflerin performanslarını birleştiren kompozit üretim çalışmalarında düşük yoğunluk oranlarında eklenen takviye malzemeleri olsa bile malzemenin fiziksel, mekanik ve kimyasal özelliklerinde bariz artışlar meydana getirmektedir. Bu çalışmada da takviye malzemeleri düşük oranda eklenerek, kompozitin özelliklerinde belirgin iyileşmeler olması beklenmiştir.

Kompozit yapilarda takviye malzemesini seçerken, mukavemet, yorulma değeri, 1 sil özellikler ve çekme direnci gibi kompozitte olması istenen özellikler göz önünde bulundurulur. Lifler arasında gerilim transferi sağlamak, takviye ve matris ara yüzeyin etkileşiminin iyi olması, liflerin korozyondan korunması kompozit malzeme seçiminde önemli olan diğer unsurlardır. $\mathrm{Bu}$ çalışmada $\mathrm{TiO}_{2}$, karbon nanotüp ve $\mathrm{ZnO}$ kullanılmıştır. $\mathrm{Bu}$ takviyelerin seçiminde kompozit malzemeye kazandırılmak ve test edilmek istenen özellikleri göz önünde bulundurulmuştur. Literatür çalışmaları incelendiğinde bu takviye malzemelerinin kullanıldığı kompozit malzemelerin özelliklerinde belirgin iyileşmeler olduğu görülmüştür (Simsek vd., 2007). Titanyum dioksit kararlı yapıs1, toksik olmaması ve güçlü oksitleyici etkisiyle antibakteriyel, antistatik özellik kazandırılmak istenen kompozit malzemelerde kullanılır (Wang vd., 2015). Bu çalışmada ise özellikle antistatik özelliğin tayini için kullanılmıştır. Ayrıca $\mathrm{TiO}_{2}$ güçlü bir fotokatalitik katalizördür (Erem ve Özcan, 2015).

Çinko oksit elektriksel özelliklerinden dolayı tekstil uygulamalarında ve bu çalışmada tercih edilen başka bir takviye malzemesidir. Antistatik özelliğiyle bilinen bu malzeme üretilen kompozitlere mekanik dayanım da kazandırmıştır. 
Bir diğer takviye malzemesi olan karbon nanotüp üstün dayanımı ve mekanik özelliklerinin yanı sıra, elektrik ve 1sıl iletkenliği yüksek olan bir malzemedir. Az miktarda kullanıldıkları takviye oranlarında bile malzemelerin özelliklerine yüksek katkıda bulunurlar (Simsek vd., 2007; Gigaz vd., 2017). Burada karbon nanotüp mukavemet, antistatik özellik için kullanılmıştır. Diğer malzemelere göre iyileştirme etkisi çok fazla olmasına karşın yüksek maliyeti karbon nanotüplerin en belirgin dezavantajıdır.

$\mathrm{Bu}$ çalışmada üretilen polimer matrisli nanokompozitlerde yöntem olarak takviye malzemeleri lif içerisine üretim aşamasında eklenmiştir. $\mathrm{Bu}$ yöntemin avantajı partiküllerin yüksek yüzey enerjileri ile liflere bağlanarak etkisini arttırmasıdır. $\mathrm{Bu}$ sayede takviye malzemeleri etkisini göstererek polimer matris ara yüzeyinde yüksek etkileşimden dolayı kompozitin mekanik özelliklerinde belirgin iyileşmeler sağlamıştır. Ayrıca diğer bir avantajı ise polimer matrisli kompozitlerde bu yöntemle üretilen çok fonksiyonlu tekstil ürünleri fonksiyonlarını uzun süre korumasıdır.

Lif matrisli polimer nanokompozitlerin eklenen çeşitli takviye elemanlarıly istenen özelliklerde malzemeler geliştirip tekstil alanında kolaylıkla uygulanabilmesi yenilikçi birçok ürün geliştirmede ve var olan üretim problemlerini azaltmakta büyük avantajdır. Diğer yandan polimerlerin geri dönüşüme imkân vermesi ve dönüşümden elde edilen malzemenin ikincil hammadde olarak endüstride tekrar kullanılabilmesi önemlidir. Gerek ekonomik koşullar gerek çevre koşulları geri dönüşüm kompozit malzemeler üretiminin ve yapilan çalışmaların artmasında önemli rol oynamıştır. Bütün bu bilgiler 1şığında r-PET polimeri gerek geri dönüşüm oranının yüksek olması gerek işleme kolaylığı ile bu çalışmada çeşitli takviye malzemeleriyle zenginleştirilerek kompozitler elde edilmiş ve çeşitli deneylerle takviye malzemelerinin etkileri incelenmiştir.

Son olarak literatür çalışmaları incelendiğinde, polimer matrisli nanokompozitlerin üretimi ve tekstil endüstrisinde kullanımıyla ilgili varolan bir çok çalışma mevcuttur. $\mathrm{Bu}$ çalışmalar incelendiğinde polimer matris olarak r-PET kullanılan çalışmaların sayısı kısıtlıdır. $\mathrm{Bu}$ çalışmada r-PET polimeri tercih edilerek ve olumlu sonuçlar alınarak var olan literatür çalışmalarına eklenmesi ve gelecek çalışmalarda kullanılmak üzere temel oluşturması hedeflenmiştir.

\section{Nanoteknoloji ve Tekstil Alanındaki Uygulamaları}

Nanomalzemelerin tekstil alanında uygulamaları son yıllarda giderek artış kazanmıştır. Nanoteknoloji ve nanomalzemeler uygun koşullarda ve miktarlarda kullanılarak tekstil ürünlerine çeşitli fonksiyonların kazandırır ve bu ürünler diğer ürünlere göre daha işlevsel özelliğe sahiptir. $\mathrm{Bu}$ işlevsel özelliklerden bazıları, su iticilik, antimikrobiyal özellik, antistatik ve mekanik ve termal dirençtir. Bütün bu özellikler nanotakviyeler sayesinde ürünlere kazandırılabilmektedir.

Tekstil ürünleri ve özellikle tekstil ipliklerinde üretim esnasında birtakım problemler oluşmaktadır. İpliklerin mukavemet, çekme dayanımı gibi mekanik özellikleri, elektriklenme problemleri nanopartiküller sayesinde azalabilmektedir. Yapılan literatür çalışmaları bu olumlu katkıları desteklemektedir (Altay ve Sarıkanat, 2019).

Filament çekim nanokompozitlerde en çok kullanılan takviye malzemeleri gümüş oksit, karbon nano tüp, grafen, $\mathrm{TiO}_{2}$ dir. $\mathrm{Bu}$ malzemelerin her biri oluşan kompozit malzemeye farklı bir özellik kazandırmaktadır. Bazı çalışmalarda UV koruması için tekstil ürünlerinin yüzeyleri polimer nanokompozit malzemelerle kaplanmıştır (Selamet vd., 2013). $\mathrm{ZnO}, \mathrm{A}_{2} \mathrm{O}_{3}, \mathrm{SiO}_{2}$ ve $\mathrm{TiO}_{2}$ UV koruması için en cok tercih edilen nanopartiküllerdir. $\mathrm{Bu}$ nanotanecikler zararlı UV ışınlarını emerek ya da yansıtarak koruma sağlanmaktadır. İletken tekstil iplikleri üretmek için iletken nanokompozitler kaplama ya da lif olarak kullanılmaktadır. Grafit, karbon, gümüş, nikel ve altın gibi iletken nanotanecikler geri dönüştürülmüş PET polimerinden üretilen liflerle beraber kullanılarak iletken nanokompozitler üretilmektedir.

İpliklere antibakteriyel özellik kazandırmak içinse uygulamalarda en çok $\mathrm{TiO}_{2}, \mathrm{Ag}, \mathrm{ZnO}, \mathrm{Cu}, \mathrm{Ga}$, $\mathrm{Au}$, karbon nanotüpler ve nano kil en çok tercih edilen antimikrobiyal özelliği olan nanopartiküllerdir. Antimikrobiyal nanotaneciklerin polimer matrislere karıştırılması sonu elde edilen lif veya filmler şeklinde kullanılarak kompozitler üretilmektedir.

\section{Materyal ve Method}

Bu çalışmada kullanılan geri dönüşüm polietilen tereftalat (r-PET) Uşak Apeks Geri Dönüşüm San. Tic. A.Ş. den granül halinde alınmıştır. CNT, 
$\mathrm{TiO}_{2}$ ve $\mathrm{ZnO}$ nanopartikül takviyeleri ise SigmaAldrıch firmasından satın alınmıştır. Geri dönüşüm polietilen teraftalat polimerinden eriyikten çekim ile filament r-PET lifler üretilmiştir. Nanopartikül takviyeleri r-pet lifinin üretimi esnasında eklenerek kompozit malzeme şeklinde üretilmiştir. $\mathrm{Bu}$ üretilen malzemelerin mikroyapı karakterizasyonu için FTIR analizi yapılmış, termal özelliklerinin incelenmesi için TGA analizi yapılmış ve eklenen nanopartikül takviyelerinin antistatik ve mekanik özelliklere etkisi incelenmiştir. Çalışma süresince kullanılan takviye malzemelerinin özellikleri Tablo 1'de verilmiştir.

Tablo 1. Kullanılan takviye malzemelerinin özellikleri (URL-1).

\begin{tabular}{cccccc}
\hline $\begin{array}{c}\text { Takviye } \\
\text { malzemesi }\end{array}$ & CAS number & $\begin{array}{c}\text { Saflık } \\
\text { değeri }(\%)\end{array}$ & $\begin{array}{c}\text { Partikül } \\
\text { çapı (nm) }\end{array}$ & $\begin{array}{c}\text { Molekül ağırlığı } \\
(\text { gr/mol) }\end{array}$ & $\begin{array}{c}\text { Erime } \\
\text { noktası }\left({ }^{\mathbf{C}} \mathbf{C}\right)\end{array}$ \\
\hline Karbon nanotüp & $308068-56-6$ & 98 & $15-25$ & - & - \\
$\mathrm{TiO}_{2}$ & $12188-41-9$ & 98 & $20-25$ & 79.87 & 1843 \\
$\mathrm{ZnO}$ & $1314-13-2$ & 97 & $20-30$ & 81.40 & 1975 \\
\hline
\end{tabular}

$\mathrm{TiO}_{2}, \quad \mathrm{ZnO}$ ve CNT takviyeleri r-PET filamentlerine $\% 0.1, \% 0.3$ ve $\% 0.5$ oranlarına eklenerek dokuz adet farklı kompozit malzeme üretilmiştir. $\mathrm{Bu}$ malzemelere sirasıyla $\mathrm{r}$ PET/0.1TiO 2 , r-PET/0.3TiO 2 , r-PET/0.5TiO 2 , rPET/0.1ZnO, r-PET/0.3ZnO, r-PET/0.5ZnO, rPET/0.1CNT, r-PET/0.3CNT, r-PET/0.5CNT kodları verilmiştir.

r-PET granülleri eriyikten filament çekimi için ilk olarak ekstrüzyona alınmıştır. Çalışma sıcaklığ $225{ }^{\circ} \mathrm{C}$ derece sıcaklığa ayarlanan ekstrüzyonda polimer eritilmiştir. Daha sonra eriyik haldeki polimere nanopartikül takviyeleri sırasıyla eklenir. Her bir takviye malzemesi için farklı oranlarda filament çekimi yapılmıştır. Son aşamada polimer ve nanotakviye karışımı basınç ile düzelere gönderilerek $250{ }^{\circ} \mathrm{C}$ derece çalışma sıcaklığında kompozit lif çekimi başlamıştır. Üretime ait şema Şekil 1' de görülmektedir (Kozanoğlu, 2006).

\section{Sonuç ve Tartışma}

$\mathrm{Bu}$ çalışmada r-PET geri dönüşüm polimerinden üretilen kompozitlere eklenen takviye malzemelerinin kompozitlerin mekanik, antistatik ve 1sıl özelliklerine etkisi incelenmiştir.

Kompozitlerin mikro yapı analizleri için FTIR spekturumları yapılmıştır. Dokuz adet kompozit numunesine takviye malzemesine göre üçerli gruplar halinde FTIR analizi yapılmış ve sonuçlar karşılaştırılmıştır. r-PET polimerinin FTIR sonucunda karakteristik olan $\mathrm{C}-\mathrm{O}$ ve $\mathrm{C}-\mathrm{H}$ pikleri gözlemlenmiştir. Kompozit numunelerin FTIR spekturumları Şekil 2'de görülmektedir.

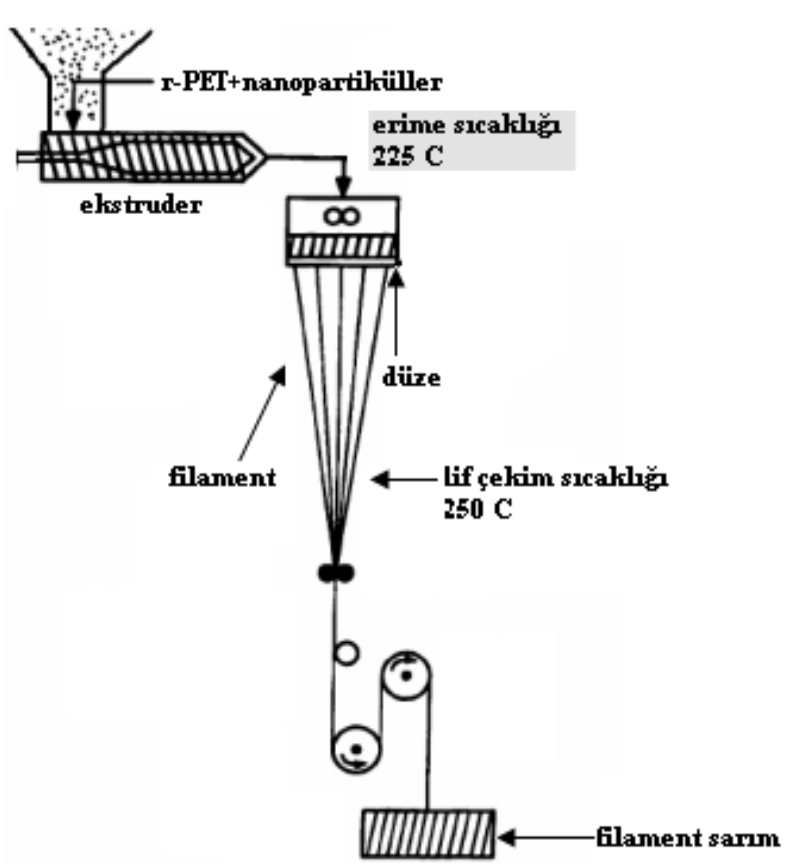

Şekil 1. Kompozitlerin filament çekim ile üretiminin şematik gösterimi (Kozanoğlu, 2006).
$\mathrm{ZnO} / \mathrm{r}-\mathrm{PET}, \quad \mathrm{TiO}_{2} / \mathrm{r}-\mathrm{PET}$ ve CNT/r-PET kompozitlerinin FTIR spekturumları incelendiğinde her üç grafiğinde birbirleriyle benzer olduğu r-PET polimerine ait karakteristik piklerin takviye malzemeli kompozitde de gözlemlendiği görülmüştür. r-PET kompozitlerine eklenen nano takviyeler, r-PET polimerinin karakteristik özelliklerine çok fazla etkide bulunmamıştır. \%0.5 takviyeli kompozitler için FTIR spekturumu incelendiğinde ise piklerin diğer oranlardaki kompozitlere göre çok az da olsa azaldığı görülür (Şekil 2). 

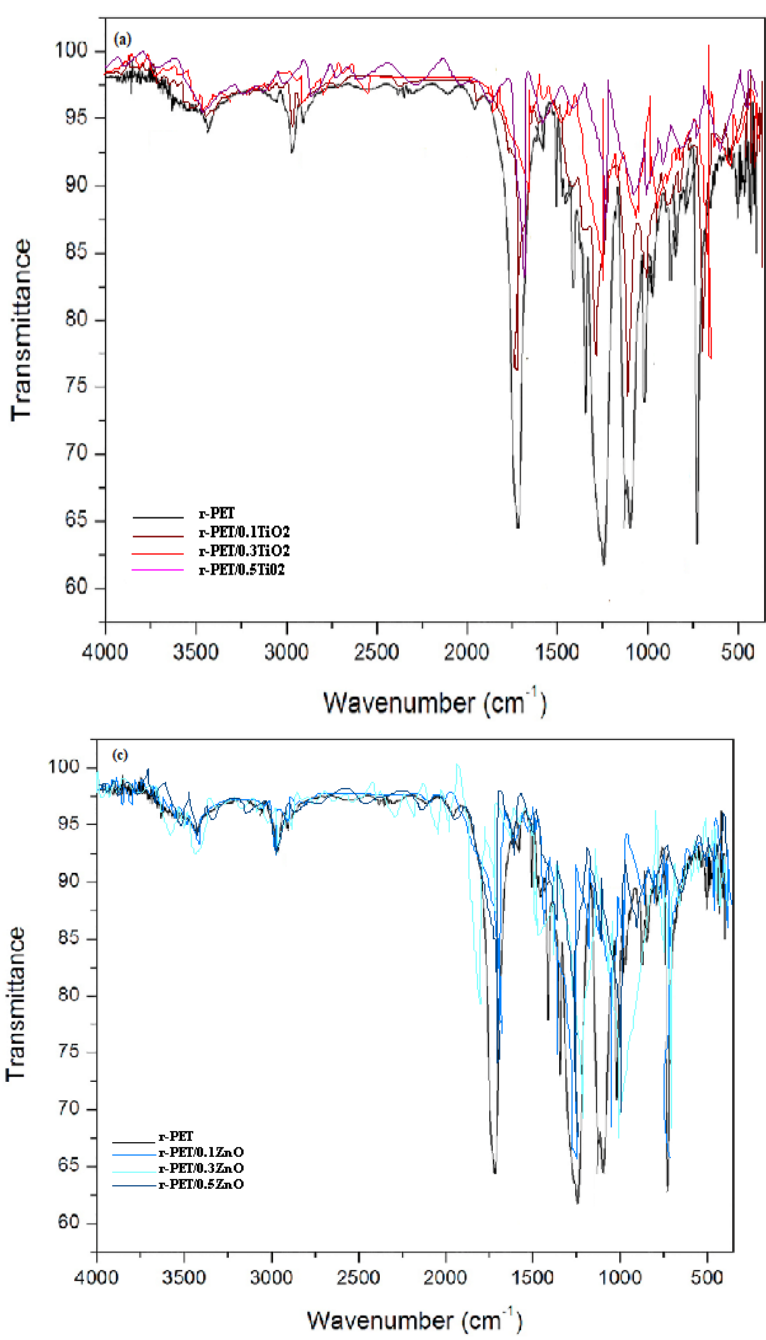

Bunun sebebi ise nanomalzemelerin kompozit malzeme içerisindeki takviye oranının artmasıyla malzeme geçirgenliğinin azalmasıdır. Ayrıca CNT siyah renge sahip olduğundan malzemenin geçirgenliğinin azalmasında diğer bir etkendir. Fakat her üç malzeme içinde geçirgenlik azalması farklı değildir. Bunun sebebi de takviye oranların en fazla $\% 0,5$ olmasidır.

Kompozitlerin termal özelliklerinin incelenmesi için numunelere TGA analizleri yapılmıştır. Şekil 3'de üç ayrı grafik sunulmuştur. Bu grafikler r$\mathrm{PET} / \mathrm{TiO}_{2}$, r-PET/ZnO ve r-PET/CNT kompozitlerini belirtmektedir.

TGA analizinde r-PET polimerinin karakteristik 1s1l bozunma ve termal kararlılık eğrisi görülmektedir. Eğrilere bakıldığında her üç farklı takviye malzemesiyle farklı ağırlık oranlarında oluşturulan 9 adet kompozit örneği için TGA eğrileri r-PET eğrisine benzer çıkmıştır. Eklenen takviye malzemelerinin r-PET polimerinin bozunma sıcaklığına kayda değer bir etkisi olmadığı düşünülmüştür. Şekil 3 'teki grafiklere bakıldığında CNT takviyeli kompozitlerde bozunma sıcaklık değerleri saf polimere göre bir

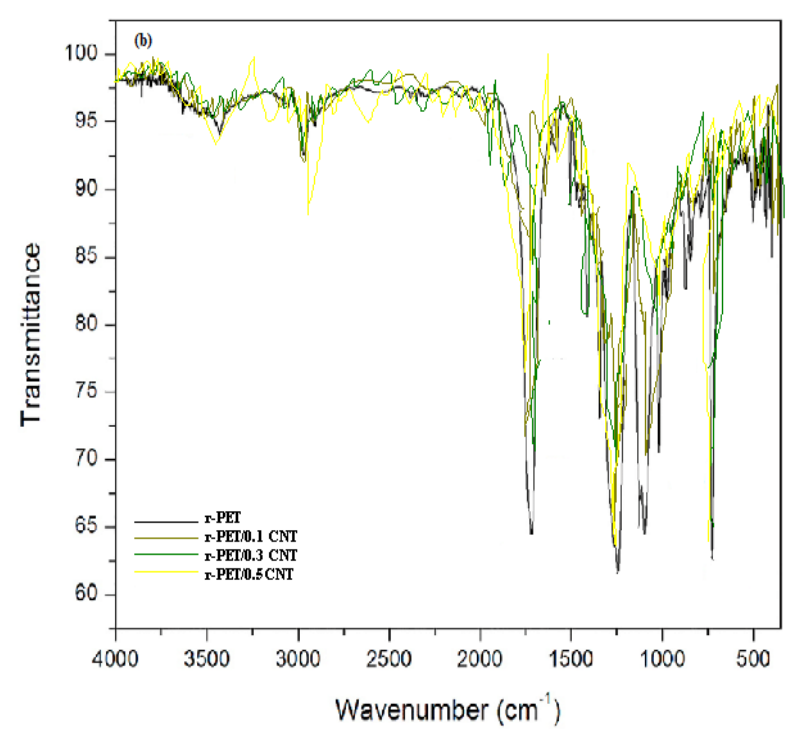

Şekil 2. Kompozit numunelerinin FTIR spekturumları. (a) $\mathrm{TiO}_{2}$ takviyeli numuneler, (b) CNT takviyeli numuneler, (c) $\mathrm{ZnO}$ takviyeli numuneler.

miktar yüksektir. Bunda CNT lerin bozunma sıcaklığının çok yüksek olmasının etkisi olduğu varsayılmıştır. Ayrıca kompozit ipliğe eklenen takviye malzemelerinin polimerin kararlılığını arttırmasi sonucu bozunma sicaklıklarında yükselme görülmesinin diğer bir nedenidir.

Konuyla ilgili olarak Arslan (2011) yaptığı tez çalışmasında çok duvarlı karbon nanotüp/poli(laktik asit) kompozitlerini çözelti dökme metoduyla hazırlamıştır. Kompozitlerin termal analiz sonuçlarına göre karbon nanotüp takviyesiyle ilk bozunma sicaklı̆g olan 328.91 ${ }^{\circ} \mathrm{C}$ 'den $347{ }^{\circ} \mathrm{C}$ 'ye kütlece $\% 0.5$ karbon nanotüp ilavesiyle artmıştır. Burada görüldüğü gibi karbon nanotüp takviyesi düşük ağırlık oranlarında bile kompozitlerin 1s1l özelliklerine belirgin iyileştirmeler yapmaktadır. Karbon nanotüp katkısıyla ilgili benzer sonuçlar bu çalışmada da elde edilmiştir.

Kompozitlerin mikroyap1 ve 1 s1l özelliklerinin tayinininden sonra mekanik testlere geçilmiştir. Tablo 2'de numunlere ait kopma mukavemeti ve kopma uzaması değerleri görülmektedir. 

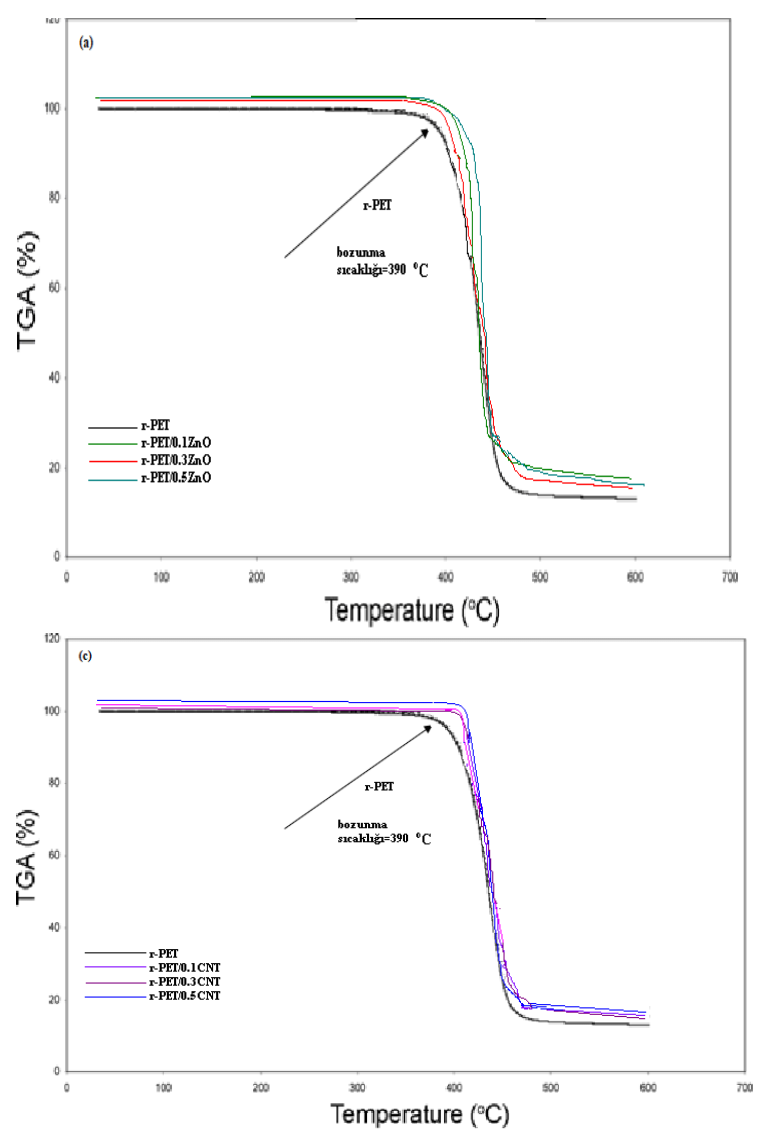

Tablo 2. Numunelerin kopma mukavemeti ve kopma uzaması değerleri.

\begin{tabular}{|c|c|c|}
\hline Malzeme & $\begin{array}{c}\text { Kopma } \\
\text { Mukavemeti } \\
\text { (MPa) }\end{array}$ & $\begin{array}{c}\text { Kopma } \\
\text { Uzaması (\%) }\end{array}$ \\
\hline r-PET & 101.3 & 16.2 \\
\hline r-PET/0.1TiO 2 & 106.7 & 14.3 \\
\hline r-PET/0.3 $\mathrm{TiO}_{2}$ & 112.1 & 11.6 \\
\hline r-PET/0.5 $\mathrm{TiO}_{2}$ & 117.5 & 9.8 \\
\hline r-PET/0.1ZnO & 105.6 & 17.3 \\
\hline r-PET/0.3ZnO & 109.7 & 19.8 \\
\hline r-PET/0.5ZnO & 115.1 & 21.5 \\
\hline r-PET/0.1CNT & 110.2 & 19.3 \\
\hline r-PET/0.3CNT & 115.6 & 23.1 \\
\hline r-PET/0.5 CNT & 121.8 & 27.3 \\
\hline
\end{tabular}

Mekanik özellikler için yapılan mukavemet testi sonuçlarında takviye malzemesi verilmemiş r-PET polimerinin mukavemet değeri takviye malzemeli kompozitlere göre daha düşüktür. $\mathrm{TiO}_{2}$ nanopartikül takviyeleri kompozitlerin kopma gerilim değerlerini gözle görülür bir biçimde arttırmıştır. Diğer yandan numunelerin kopma uzaması yüzde oranları artan $\mathrm{TiO}_{2}$ takviyeleriyle azalma göstermiştir. Bunun sebebinin $\mathrm{TiO}_{2}$ partiküllerinin yapısal olarak diğer takviyelere oranla daha tok ve sert olmasıdır. Kompozit

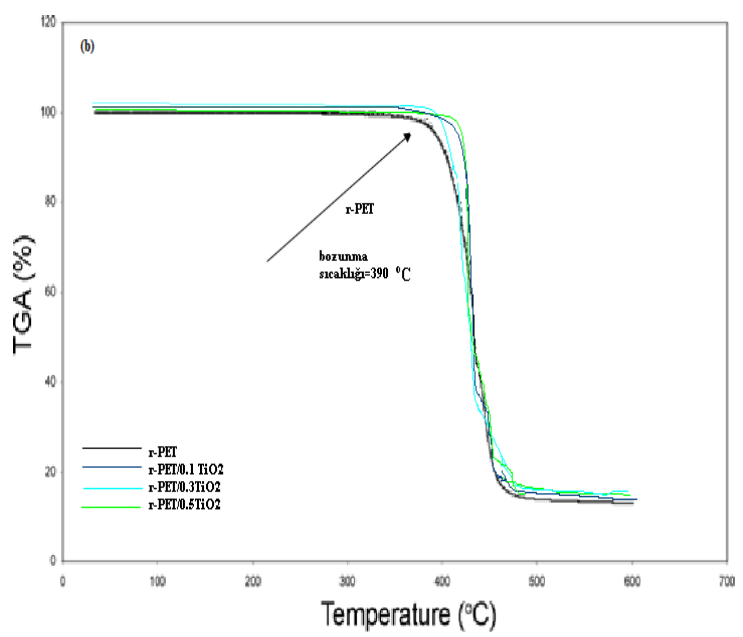

Şekil 3. Kompozit örneklerinin TGA analizleri. (a) $\mathrm{ZnO}$ takviyeli numuneler, (b) $\mathrm{TiO}_{2}$ takviyeli numuneler, (c) CNT takviyeli numuneler.

içerisindeki $\mathrm{TiO}_{2}$ miktarı arttıkça malzemelerin kopma uzaması azalmıştır. Yani malzeme giderek boynuzumsu ve kırılgan bir hal almıştır.

$\mathrm{ZnO}$ takviyesi yapılan kompozitlerde kopma gerilimi ve kopma uzaması artış göstermiştir (Tablo 2). ZnO partikülleri esnek yapıda olduğu için malzemeye bir miktar esneklik kazandırarak yüzde uzaması arttırmıştır. CNT takviyeli numunelerin kopma mukavemeti ve kopma uzaması değerleri incelendiğinde en yüksek değerleri aldığ görülür. CNT ile alakalı birçok literatür araştırmasında malzemenin üstün mekanik özelliklerinden bahsedilmiştir. Takviye olarak eklendiği kompozit malzemelerin mukavemet, kopma uzaması, young modülü gibi mekanik özelliklerinde belirgin iyileşmeler olduğu görülmüştür (Gigaz vd., 2017).

Erem ve Ozcan (2013) yaptıkları bir çalışmada 0 , $0.5,1,3$ ve $5 \%$ ağırlık oranlarında $\mathrm{ZnO}$ kullanmışlardır. Eriyikte birleştirme ile $\mathrm{PP} / \mathrm{ZnO}$ kompozitleri elde edilmiştir. Sonuçlara göre $\mathrm{ZnO}$ ağırlık oranı arttıkça kompozit malzemenin mekanik ve 1sıl özelliklerine olumlu etki yaptığı görülmüştür. Bunun sebebi olarak $\mathrm{ZnO}$ partiküllerinin matris arayüzey etkileşiminin güçlü olmasını göstermişlerdir. Benzer şekilde bu çalışmada $\mathrm{ZnO} / \mathrm{r}$-PET kompozitlerinin mekanik 
ve 1s1l özelliklerinde r-PET'e göre iyileşme olmuştur.

Kompozitlere eklenen üç malzemeninde numunelerin mukavemetine katkısı olumlu yönde olmuştur. $\mathrm{Bu}$ duruma $\mathrm{CNT}, \mathrm{TiO}_{2}$ ve $\mathrm{ZnO}$ partikül takviyelerinin matris içerisinde homojen dağılarak kompozit ipliğe uygulanan gerilimin malzemenin her yerine eşit dağılması sonucu direnci arttırmasının neden olduğu düşünülmektedir. Kompozitlerin elastisite modül değerleri Tablo 3 'de verilmiştir.

Tablo 3. Kompozit malzemelerin elastisite modülü.

\begin{tabular}{cc}
\hline Malzeme & $\begin{array}{c}\text { Elastisite modülü } \\
(\mathbf{G P a})\end{array}$ \\
\hline $\mathrm{r}-\mathrm{PET}$ & 93.7 \\
$\mathrm{r}-\mathrm{PET} / 0.1 \mathrm{TiO}_{2}$ & 95.85 \\
$\mathrm{r}-\mathrm{PET} / 0.3 \mathrm{TiO}_{2}$ & 101.52 \\
$\mathrm{r}-\mathrm{PET} / 0.5 \mathrm{TiO}_{2}$ & 117.63 \\
$\mathrm{r}-\mathrm{PET} / 0.1 \mathrm{ZnO}$ & 97.59 \\
$\mathrm{r}-\mathrm{PET} / 0.3 \mathrm{ZnO}$ & 119.12 \\
$\mathrm{r}-\mathrm{PET} / 0.5 \mathrm{ZnO}$ & 130.36 \\
$\mathrm{r}-\mathrm{PET} / 0.1 \mathrm{CNT}$ & 112.55 \\
$\mathrm{r}-\mathrm{PET} / 0.3 \mathrm{CNT}$ & 132.87 \\
$\mathrm{r}-\mathrm{PET} / 0.5 \mathrm{CNT}$ & 150.61 \\
\hline
\end{tabular}

Tablo 3'e göre elastisite modülü maksimum değerini $\% 0.5$ oranında CNT takviyeli nanokompozit filamentinde almıştır. Karbon nanotüp eşsiz esneklik özelliğine sahiptir. Literatür çalışmaları incelendiğinde CNT takviyeli nanokompozitlerin yüzde uzamaları diğer numunelerle kıyaslandığında daha yüksek değerler almıştır (Gigaz vd., 2017). $\mathrm{TiO}_{2}$ ve $\mathrm{ZnO}$ nanopartiküllerinin de r-PET polimer kompozitlerinin çekme özelliğini de olumlu etkilediği görülmüştür. $\mathrm{ZnO}$ yapı olarak $\mathrm{TiO}_{2}$ den daha fazla esnek karakter gösterir. $\mathrm{TiO}_{2}$ ise $\mathrm{ZnO}$ ve CNT takviyelerinden daha fazla sertlik değerine sahiptir. $\mathrm{Bu}$ yüzden kompozitlerin elastisite modülleri ölçüldüğünde en az olumlu etki $\mathrm{TiO}_{2}$ kompozit numunelerinde görülmüştür.

Uzun vd. (2014) yapmış oldukları bir çalışmada ağırlıça \%0.5, \%1, \%2 ve \%4 oranlarında $\mathrm{TiO}_{2}$ takviyesiyle polipropilen kompozitler üretmiş ve vidalı ekstruder kullanmışlardır. Elde edilen sonuçlara göre kompozit numunelerine $\mathrm{TiO}_{2}$ ilavesi ile kompozitlerin mekanik özelliklerini olumlu olarak etkilemiştir fakat $\% 0.5$ oranında nano- $\mathrm{TiO}_{2}$ ilavesi genellikle kompozitlerin özellikleri üzerinde olumsuz etkiye sebep olmuştur. Kompozitlerin Elastikiyet Modülleri
$\% 0.5$ nano- $\mathrm{TiO}_{2}$ içeren kompozitlerde düştüğü bulunmuştur. $\% 1$ ve $\% 2$ oranında partikül içeren kompozitlerde elastikiyet modülü değişmezken, $\% 4$ partikül ilavesiyle kompozitlerin elastikiyet modülleri yükselmiştir. Ayrıca kompozitlerin; su alma, yoğunluk, çekme direnci, eğilme direnci, DTA, TGA özelliklerine bakıldığında nano- $\mathrm{TiO}_{2}$ partiküllerin ilavesinin pozitif etkilere sahip olduğu belirlenmiştir. Çalışma sonuçları genel $\begin{array}{llll}\text { olarak yorumlandığında } & \mathrm{TiO}_{2} & \text { takviyeli }\end{array}$ kompozitlerin mekanik ve 1 s1l özelliklerinde literatürle benzer sonuçlar elde edilmiştir.

Üretilen kompozit numunelerinin elektriksel direnç özellikleri elektrometre (Keithley 6517 B) ile ölçülmüştür. Ölçümlerin sonucunda elde edilen kompozitlerin yüzey dirençleri Tablo 4'te görülmektedir.

Tablo 4. Kompozit numunelerinin elektrik dirençleri

\begin{tabular}{cc}
\hline Malzeme & $\begin{array}{c}\text { Elektrik direnci, } \\
\mathbf{R}_{\mathbf{s}}(\mathbf{o h m})\end{array}$ \\
\hline $\mathrm{r}-\mathrm{PET}$ & $4.2^{*} 10^{20}$ \\
$\mathrm{r}-\mathrm{PET} / 0.1 \mathrm{TiO}_{2}$ & $1.24 * 10^{20}$ \\
$\mathrm{r}-\mathrm{PET} / 0.3 \mathrm{TiO}_{2}$ & $9.67 * 10^{19}$ \\
$\mathrm{r}-\mathrm{PET} / 0.5 \mathrm{TiO}_{2}$ & $6.65 * 10^{19}$ \\
$\mathrm{r}-\mathrm{PET} / 0.1 \mathrm{ZnO}$ & $1.10^{*} 10^{20}$ \\
r-PET$/ 0.3 \mathrm{ZnO}$ & $8.76^{*} 10^{19}$ \\
r-PET$/ 0.5 \mathrm{ZnO}$ & $5.59 * 10^{19}$ \\
$\mathrm{r}-\mathrm{PET} / 0.1 \mathrm{CNT}$ & $5.56 * 10^{19}$ \\
r-PET/0.3CNT & $2.16^{*} 10^{19}$ \\
r-PET/0.5 CNT & $4.24 * 10^{18}$ \\
\hline
\end{tabular}

Antistatik özelliklerin incelenmesi için yapılan deneyler sonucu nanopartikül takviyelerinin kompozit malzemelerin antistatik özelliklerini olumlu yönde etkilediği görülmüştür. PET polimeri en kuvvetli yalıtkanlar arasındadır. Dolayısıyla elektrik direnci çok yüksektir. Ancak tablodan da görüldüğü üzere takviye malzemeleriyle güçlendirilmiş kompozitlerin elektriksel özelliklerinde iyileşme görülmüştür. Özellikle CNT takviyeli kompozitlerde direnç iyileşmesi diğerlerine göre daha fazladır. CNT üstün elektriksel özelliklere sahiptir. Elektrik iletkenliğinin bu kadar yüksek olmasının nedeni yapısında bulunan fazla sayıda $\pi$-bağlarıdır $(C=C$ bağı). Elektronlar bu bağlar sayesinde daha hızlı ve kolay iletilmektedir. $\mathrm{ZnO} \mathrm{veTiO}_{2}$ elektriksel özellikleri kuvvetli olan diğer iki metal oksittir. $\mathrm{Bu}$ malzemelerin eklendiği kompozit numunelerinde de r-PET polimerinin $10^{20} \mathrm{ohm}$ civarında olan elektrik direnci $10^{19}-10^{18} \mathrm{ohm}$ düzeyine kadar iyileşmiştir. 
Zhang vd. (2010) eriyikte birleştirme yöntemi ile PET/grafen nanokompozitleri hazırlamışlardır. Sonuçlara göre kompozit içerisindeki grafen oranı arttıça PET/grafen nanokompozitinin iletkenliğinin hızla arttı̆̆ını, nanokompozitin elektriksel iletkenliği \%3'lük grafen eklenmesiyle $2.11 \mathrm{~s} / \mathrm{m}$ seviyesine çıtığını rapor etmişlerdir. Bir başka çalışmada Agrawal vd. (2014) PET matrisli nanokompozitleri $\mathrm{ZnO}$ takviye malzemesi kullanarak üretmişlerdir. Numunelerin elektriksel ölçümleri sonucunda $\mathrm{ZnO}$ nanotaneciklerin eklenmesiyle ve matris içerisindeki bileşiminin arttırılmasıyla beraber PET polimerinin iletken hale geldiği görülmüştür. Burada r-PET polimerine eklenen $\mathrm{TiO}_{2}, \mathrm{ZnO}$ ve CNT takviyelerinin elektriksel özelliklere olumlu katkıda bulunması beklenen bir sonuçtur. Her üç takviye için yapılan çalışmalar incelendiğinde matris fazında kullanılan farklı polimerlerle elde edilen kompozit malzemelerin elektriksel özelliklerinde iyileşmeler olduğu görülmüştür (Simsek vd., 2007).

$\mathrm{Bu}$ çalışmada r-PET geri dönüşüm polimeri kullanılarak elde edilen nanopartikül takviyeli kompozit malzemelerin mekanik, mikroyapı ve termal özellikleri incelenmiştir. Geri dönüşüm işleminin kolay olması ve tekstil endüstrisine uygulanabilirliği matris olarak kullanılan r-PET polimeriyle alakalı çalışmaların artmasına neden olmuştur. $\mathrm{TiO}_{2}, \mathrm{ZnO}$ ve $\mathrm{CNT}$ takviyeleri ise üstün mekanik, antistatik, termal özelliklere sahiptir. Eriyikte birleştirme yöntemiyle $120 \mathrm{~nm}$ kalınlığında filament çekim yöntemiyle üretilen nanokompozitlere yapılan testler sonucunda her üç takviye malzemesiyle farklı oranlarda üretilen kompozitlerin mekanik, termal ve antistatik özelliklerine etkileri olumlu yönde olmuştur. Yapılan bu çalışmada literatüre katkı sağlayacak sonuçlar elde edilmiştir.

\section{Kaynaklar}

Agrawall, H., Saraswat, K., ve Awasthi, K. 2014. ZnO Doping in PET Matrix Enhances Conductivity of PET-ZnO Nanocomposites. Advanced Electrochemistry, 1, 1-6.

Altay, L. ve Sarıkanat, M., 2019. Karbon Lif Yüzey Modifikasyonunun Karbon Lif ve Karbon Lif Takviyeli Kompozit Malzemelerin Özelliklerine Etkilerinin İncelenmesi. Tekstil ve Mühendis, 26(113), 25-32.

Arslan, F., 2011. Karbon Nanotüp Takviyeli Polimer Nanokompozit Geliştirilmesi. Yüksek Lisans Tezi, Gazi Üniversitesi Fen Bilimleri Enstitüsü. Ankara, 148s.
Awad, A.S. ve Khalaf, M.E., 2016. Improvement of Chemical and Thermal Properties of Polyethylene Terephthalate (PET) by Using Multi-Walled Carbon Nanotubes (MWCNTS). International Journal of Materials Science and Applications, 6, 297-301.

Erem, A. ve Özcan, G., 2015. Polipropilen/Titanyum Dioksit Nanokompozit Liflerin Üretimi ve Karakterizasyonu. Tekstil ve Mühendis, 27(99), $1-3$.

Erem, A., Özcan G. ve Skrifvars, M., 2013. In Vitro Assessment of Antimicrobial Polypropylene/Zinc Oxide Nanocomposite Fibers. Textile Research Journal, 83(20), 21522163.

Gigaz, J., Bradford, P. ve Shao, L., 2017. RadiationInduced Mechanical Property Changes of CNT Yarn. Nuclear Instruments and Methods in Physics Research B: Beam interactions with Materials and Atoms, 409, 268-271.

Harry, L., James, F. ve Mark, E., 1996. Nanocomposites Prepared by Threading Polymer Chains Through Zeolites, Mesoporous Silica, or Silica Nanotubes. Chemical Materials, 8, 1735-1738.

Kozanoğlu, G.S., 2006. Elektrospinning Yöntemiyle Nanolif Üretim Teknolojisi. Yüksek Lisans Tezi, İstanbul Teknik Üniversitesi Fen Bilimleri Enstitüsü. İstanbul, $161 \mathrm{~s}$.

Ma, H., Li, Y., Shen, Y., Zie, L. ve Wang, D., 2016. Effect of Linear Density and Yarn Structure on the Mechanical Properties of Ramie Fiber Yarn Reinforced composites. Composites: Part A, 87, 98-108.

Montazer, M. ve Morshedi, S., 2014. Photo Bleaching of Wool Using Nano $\mathrm{TiO}_{2}$ Under Daylight Irradiation. Journal of Industrial and Engineering Chemistry, 20, 83-90.

Selamet, Y., Meriç, Z. ve Özyüzer, L., 2013. Antistatic and Antibacterial Properties of Metal Coated PP Fibers by Magnetron Sputtering. Tekstil ve Mühendis, 78, 2-5.

Simsek, Y., Ozyuzer, L., Seyhan, A. T., Tanoglu, M. ve Schulte, K., 2007. Temperature Dependence of Electrical conductivity in Double-Wall and Multi-Wall Carbon Nanotube/polyester Nanocomposites. Journal of Materials Science, 42, 9689-9695.

Subası, A., Zurnac1, M., Kahyaoğlu, A. ve Demir, E., 2017. Polyester/Grafen Kompozitlerinin Mekanik ve Termal Özelliklerinin İncelenmesi. El-Cezeri Journal of Science and Engineering, $3,472-481$. 
Tan, N.L. ve Thomas, H., 2016. A Review of the Water Barrier Properties of Polymer/Clay and Polymer/Graphene Nanocomposites. Journal of Membrane Science, 514, 595-612.

Telli, A., Özdil, N. ve Babaarslan, O., 2012. PET şişe Atıklarının Tekstil Endüstrisinde Değerlendirilmesi ve Sürdürülebilirliğe Katkısı. Tekstil ve Mühendis, 19(86), 49-55.

URL-1, https://www.sigmaaldrich.com

Uzun, G., Gümüs, H., Yıldız, S., Gümüs, S., Aydemir, D. ve Bardak, T. 2014. $\mathrm{TiO}_{2}$ İlaveli Polipropilen Nanokompozitlerin Hazırlanması ve Karakterizasyonu, II. Ulusal Akdeniz Orman ve Çevre Sempozyumu, Isparta.

Wang, H., Xian, G. ve Li, H., 2015. Grafting of Nano$\mathrm{TiO}_{2}$ onto Flax Fibers and the Enhancement of the Mechanical Properties of the Flax Fiber and Flax Fiber/Epoxy Composite. Composites: Part A, 76, 172-180.

Wu, Q., Li, M., Gu, Y., Wang, S., Yao, L. ve Zhang, Z., 2016. Effect of Sizing on Interfacial Adhesion of Commercial High Strength Carbon
Fiber Reinforced Resin Composites. Polymer Composites, 37(1), 254-261.

Zahed, B. ve Monfared, H., 2015. A Comparative Study of Silver-Grapheneoxide Nanocomposites As a Recyclable Catalyst for the Aerobic Oxidation of Benzyl Alcohol: Support Effect. Applied Surface Science, 328, 536-547.

Zahouily, M., Safi, M. ve Quadil, B., 2017. Surface Modification of Knit Polyester Fabric for Mechanical, Electrical and UV Protection Properties by Coating with Graphene Oxide, Graphene and Graphene/Silver Nanocomposites. Applied Surface Science, 414, 292-302.

Zhang, H., Zheng, W., Yan, Q., Yang, Y., Wang, J. ve Lu, Z., 2010. Electrically Conductive Polyethylene Terephtlhalate/Graphene Nanocomposites Prepared by Melt Compounding. Polymer, 51, 1191-1196.

Zhu, J., Charles, A. ve Wilkie, A., 2000. Thermal and Fire Studies on Polystyrene-Zincoxide Nanocomposites. Polymer International, 49, 1158-1163. 